\title{
Temperature dependence of the properties of vapor-deposited polyimide
}

\author{
F. Y. Tsai \\ Laboratory for Laser Energetics, University of Rochester, 250 East River Road, Rochester, \\ New York 14623-1299 and Department of Chemical Engineering, University of Rochester, Rochester, \\ New York 14623-1299 \\ T. N. Blanton \\ Eastman Kodak Company, Research and Development Laboratories, Rochester, New York 14650-2106 \\ D. R. Harding a) and S. H. Chen \\ Laboratory for Laser Energetics, University of Rochester, 250 East River Road, Rochester, \\ New York 14623-1299 and Department of Chemical Engineering, University of Rochester, Rochester, \\ New York 14623-1299
}

(Received 5 August 2002; accepted 2 January 2003)

\begin{abstract}
The Young's modulus and helium gas permeability of vapor-deposited poly $\left(4,4^{\prime}\right.$-oxydiphenylenepyromellitimide) were measured at cryogenic and elevated temperatures $(10-573 \mathrm{~K})$. The Young's modulus decreased with increasing temperature from $5.5 \mathrm{GPa}$ at $10 \mathrm{~K}$ to $1.8 \mathrm{GPa}$ at $573 \mathrm{~K}$. The temperature dependency of the permeability followed the Arrhenius' relationship, with different activation energy for permeation for samples imidized under different conditions. The effect of the imidization conditions on the permeation properties could be explained in terms of morphology/crystallinity as determined by x-ray diffraction techniques. Imidizing in air instead of nitrogen increased the permeability while lowering the activation energy for permeation and crystallinity. Imidizing at higher heating rates (in nitrogen) resulted in higher permeability, lower activation energy for permeation, and larger and fewer crystallites with better-aligned lattice planes. (C) 2003 American Institute of Physics. [DOI: 10.1063/1.1555838]
\end{abstract}

\section{INTRODUCTION}

Polymides are used extensively in a variety of hightechnology applications because of their excellent thermal, electrical, and mechanical properties. In recent developments of the inertial confinement fusion (ICF) program, polyimides are utilized as an ablator material that is made into spherical microcapsules to contain hydrogen isotopes as fusion fuel. ${ }^{1,2}$ The ICF application involves handling and processing the polyimide microcapsules at a wide temperature range, 10$573 \mathrm{~K}$, where pressure differentials across the capsule wall are created that can buckle or burst the capsules. ${ }^{3}$ The survival of the microcapsules requires precise control of the pressure inside and outside the microcapsules at all stages of operation, which calls for a thorough knowledge of the mechanical properties and gas permeability of the microcapsules at the operating temperature range. The properties of solution-cast poly $\left(4,4^{\prime}\right.$-oxydiphenylenepyromellitimide) (PMDA-ODA polyimide) at nonambient temperatures have been reported: gas permeability at $323-523 \mathrm{~K}$ and mechanical properties at $4.2-473 \mathrm{~K} ;{ }^{4,5}$ however, equivalent data are unavailable for vapor-deposited polyimide. In previous studies, PMDA-ODA polyimide microcapsules were developed based on vapor deposition polymerization, ${ }^{6,7}$ and the roomtemperature properties were characterized. ${ }^{2,3}$ This work presents the results of our continuing effort to extend the characterization of vapor-deposited polyimide to elevated and

\footnotetext{
a) Author to whom correspondence should be addressed; electronic mail: fengtsai@yahoo.com
}

cryogenic temperatures. The effects of imidization conditions on the temperature-permeability relationship were studied, and the corresponding morphology was examined using $\mathrm{x}$-ray diffraction.

\section{EXPERIMENT}

\section{A. Sample preparation}

Polyimide microcapsules were prepared via a two-step process: (1) The monomers, pyromellitic dianhydride (PMDA) and 4,4'-oxydianiline (ODA), were vapordeposited into spherical shells made of poly- $\alpha$-methylstyrene $(\mathrm{PAMS})^{8}$ to form a layer of poly(amic acid); (2) the coated shells were thermally cured to convert poly(amic acid) into polyimide (imidization). The PAMS shells decomposed at elevated temperatures into gaseous products that permeate through the polyimide layer, leaving behind freestanding polyimide capsules. Imidization was carried out in a NEY Centurion VPM furnace with programmable temperatures (accuracy $= \pm 0.1{ }^{\circ} \mathrm{C}$ ). The furnace was purged with a constant flow of nitrogen $\left(7.5 \mathrm{sr} \mathrm{cm}^{3} / \mathrm{min}\right)$ throughout imidization. The temperature cycle for imidization involved three steps: (1) heating from 25 to $300^{\circ} \mathrm{C}$ at $0.1^{\circ} \mathrm{C} / \mathrm{min}$; (2) soaking at $300^{\circ} \mathrm{C}$ for $6 \mathrm{~h}$; (3) cooling to $25^{\circ} \mathrm{C}$ at $5{ }^{\circ} \mathrm{C} / \mathrm{min}$. A detailed description of the sample preparation process can be found elsewhere. ${ }^{3}$ The reaction scheme of the formation of polyimide is shown in Fig. 1.

Flat films were prepared similarly, except that sodium chloride disks (purchased from International Crystal Laboratories) were used as substrates, which were dissolved in de- 
PMDA

ODA
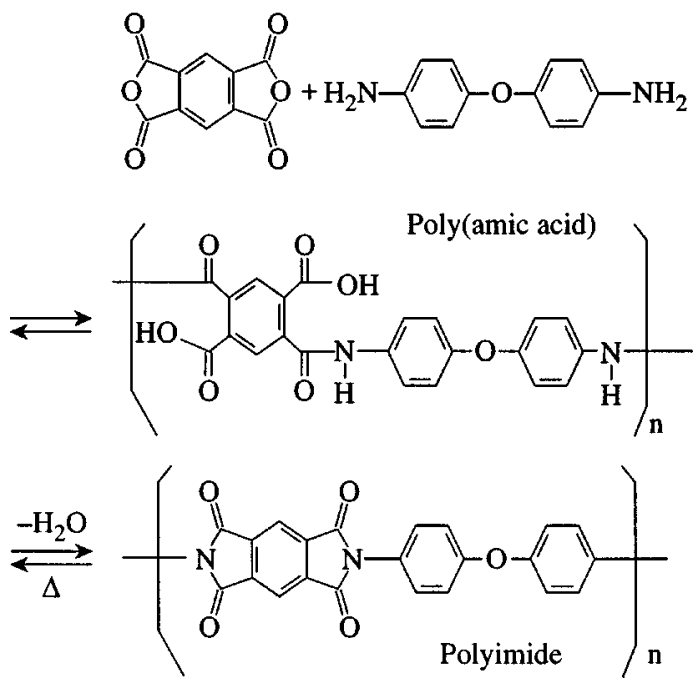

FIG. 1. Reaction scheme of the formation of PMDA-ODA polyimide.

ionized water to lift the films after imidization. The lifted films were vacuum dried at $80^{\circ} \mathrm{C}$ for $24 \mathrm{~h}$. A detailed description of the fabrication process can be found elsewhere. ${ }^{3}$

The microcapsule samples had an outer diameter of 950-1200 $\mu \mathrm{m}$ and a wall thickness of $0.7-6 \mu \mathrm{m}$; the film samples were $15 \mathrm{~mm} \times 15 \mathrm{~mm} \times 25 \mu \mathrm{m}$. The microcapsules were inspected before testing to ensure a minimum sphericity of $99.8 \%{ }^{3}$ Kapton HN films purchased from Dupont with the same dimensions as the flat vapor-deposited films were tested for comparison.

To study the effects of imidization conditions on the permeability, the conditions, including imidizing atmosphere and heating rate, were varied. The atmosphere studied included air and nitrogen, and the heating rates included $0.1,1$, 5 , and $10^{\circ} \mathrm{C} / \mathrm{min}$. In the air versus nitrogen study, the heating rate was $0.1^{\circ} \mathrm{C} / \mathrm{min}$; in the heating rate study, the atmosphere was nitrogen.

\section{B. Young's modulus and permeability}

The Young's modulus was determined by the buckle test where uniform pressure differentials of helium or nitrogen were applied across the microcapsule wall to cause buckling. ${ }^{3}$ For thin-walled spherical capsules, the Young's modulus is related to the buckling pressure differential by ${ }^{9}$

$$
P_{\text {buckle }}=\frac{2 E}{\sqrt{3\left(1-\nu^{2}\right)}}\left(\frac{w}{r}\right)^{2},
$$

where $E$ is the Young's modulus, $\nu$ the Poisson's ratio $(=0.34),{ }^{10} P_{\text {buckle }}$ the buckling pressure differential, and $r$ and $w$ the radius and wall thickness of the capsule, respectively. Figure 2 depicts the schematic of the experimental procedures. For elevated-temperature measurements, 295$573 \mathrm{~K}$, the sample holder was heated with a Watlow cartridge heater and a Cole-Parmer DigiSens temperature controller to an accuracy of $0.1{ }^{\circ} \mathrm{C}$. For cryogenic measurements at $10-$

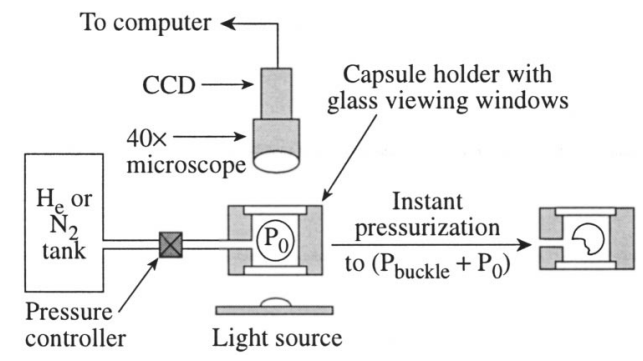

FIG. 2. Schematic of the buckle test setup and procedures.

$295 \mathrm{~K}$, the sample holder was cooled with a Leybold Coolpower 130 Cryocooler and a Lakeshort 321 temperature controller.

The gas permeability was measured with both microcapsule and film samples using experimental setups shown in Fig. 3. The downstream volume of the samples was initially evacuated to $10^{-5}$ Torr before each test. A constant pressure of helium (1-2 atm) as maintained at the upstream side of the sample during measurement. The permeation rate through the sample was monitored using an Edwards Spectron 600D leak detector. Knowing the permeation rate, the permeability coefficient was calculated as given by

$$
K_{P}=\frac{R_{P}}{P_{H}-P_{L}} \frac{L}{A},
$$

where $K_{p}$ is the permeability coefficient, $R_{P}$ the molar permeation rate, $P_{H}$ the upstream pressure, $P_{L}$ the downstream pressure, and $L$ and $A$ the thickness and surface area of the samples, respectively. For nonambient temperature measurements, the cooling and heating mechanisms were the same as those for the buckle test. Knowing the temperature dependency of the permeability, the activation energy for permeation was calculated according to the Arrhenius' relation as given by

$$
K_{P}=K_{P 0} e^{-\left(E_{P} / R T\right)},
$$

where $K_{P 0}$ is a temperature-independent pre-exponential factor, $R$ the gas constant, and $T$ the temperature.

\section{X-ray diffraction and density measurement}

The morphology of vapor-deposited polyimide was examined using x-ray diffraction. Measurements were made in three orientations: reflection, transmission, and grazing angle. The tested samples included films and flattened micro-

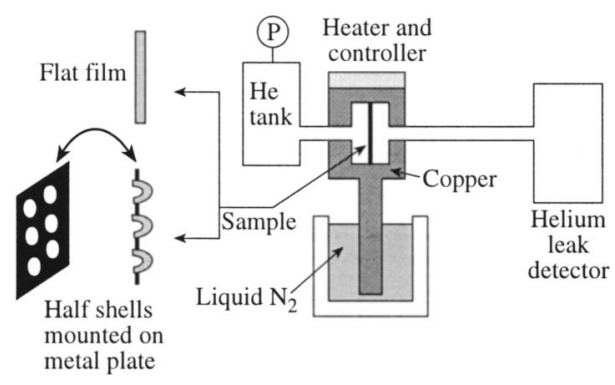

FIG. 3. Schematic of the permeation measurement with polyimide microcapsules and films. 


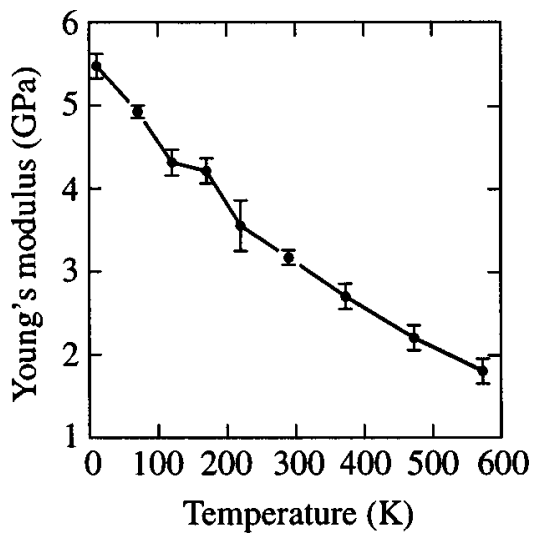

FIG. 4. Temperature dependency of the Young's modulus of polyimide microcapsules.

capsules. A Rigaku D2000 Bragg-Brentano diffractometer ${ }^{11}$ equipped with a copper rotating anode, diffracted beam graphite monochromator, and scintillation detector was used to obtain reflection-mode diffraction patterns. Data were collected as continuous scans at a scan rate of $2^{\circ} 2 \theta / \mathrm{min}$. A Bruker AXS microdiffractometer ${ }^{12}$ equipped with a copper rotating anode, Goebel mirrors, $0.5 \mathrm{~mm}$ collimator, and twodimensional general area detector diffraction system was used to obtain transmission- and grazing-angle mode diffraction patterns. Each microdiffractometer data was collected until $10^{7}$-total-counts integrated intensity was achieved. The correlation length of the polyimide crystallites was estimated using the Scherrer formula, as given by ${ }^{13}$

$$
\ell=\frac{K \lambda}{\beta \cos \theta},
$$

where $\ell$ is the correlation length, $K$ the Scherrer constant calibrated to be 0.9 for the instrument used, $\lambda$ the $\mathrm{x}$-ray wavelength $(1.54 \AA), \beta$ the half-width of the diffraction peak, and $\theta$ the diffraction angle.

The density of polyimide films and capsules was measured using a Techne TE-10A density column with an aqueous zinc chloride solution. The samples were allowed $24 \mathrm{~h}$ in the column to settle into the equilibrium position. The measurements were performed by General Atomics to an accuracy of $0.001 \mathrm{~g} / \mathrm{cm}^{3}$.

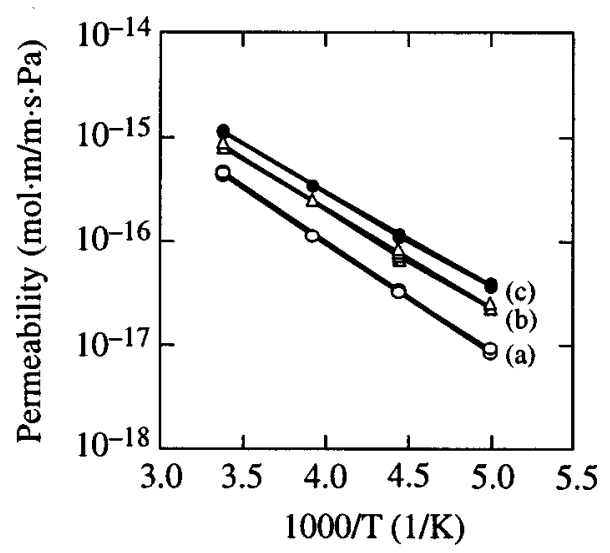

FIG. 5. Temperature dependency of the helium permeability through (a) vapor-deposited polyimide imidized in $\mathrm{N}_{2}$. (b) Kapton polyimide, and (c) vapor-deposited polyimide imidized in air. The activation energy for permeation is $20.1,18.2$, and $17.4 \mathrm{KJ} / \mathrm{mol}$ for (a), (b), and (c), respectively.

\section{RESULTS AND DISCUSSION}

Figure 4 shows the temperature dependency of the Young's modulus of polyimide microcapsules between 10 and $573 \mathrm{~K}$. The Young's modulus decreased with increasing temperature with a nearly linear relationship. The values were $1.8 \mathrm{GPa}$ at $573 \mathrm{~K}$ and $5.5 \mathrm{GPa}$ at $10 \mathrm{~K}$.

The temperature dependency of the helium permeability of vapor-deposited and Kapton polyimide is compared in Fig. 5, and the values of the activation energy for permeation are summarized in Table I. Compared to Kapton, the vapordeposited samples possessed consistently lower permeability within the measured temperature range and higher activation energy for permeation. The activation energy for permeation of polymeric materials is determined mainly by the segmental mobility of the polymer chains; i.e., the higher the segmental mobility, the easier the chain segments can rearrange to open up a "gap" large enough for gas molecules to permeate through, therefore the lower the activation energy for permeation..$^{14,15}$ The lower permeability and higher activation energy for permeation of the vapor-deposited polyimide may be attributed to the presence of cross-linking ${ }^{3}$ that limits the segmental mobility of the polymer chains.

Figure 5 also compares the temperature dependency of permeability and the activation energy for permeation of vapor-deposited polyimide imidized in nitrogen and air at-

TABLE I. Activation energy for permeation for Kapton and vapor-deposited polyimide imidized under different conditions.

\begin{tabular}{|c|c|c|c|c|c|c|}
\hline & \multirow[b]{3}{*}{ Katon $\mathrm{HN}$} & \multicolumn{4}{|c|}{ Vapor-deposited polyimide } & \multirow[b]{3}{*}{ Air imidized } \\
\hline & & \multicolumn{4}{|c|}{$\mathrm{N}_{2}$ imidized } & \\
\hline & & $0.1^{\circ} \mathrm{C} / \mathrm{min}$ & $1{ }^{\circ} \mathrm{C} / \mathrm{min}$ & $5^{\circ} \mathrm{C} / \mathrm{min}$ & $10{ }^{\circ} \mathrm{C} \min$ & \\
\hline $\begin{array}{l}\text { Activation } \\
\text { energy for } \\
\text { permeation } \\
(\mathrm{kJ} / \mathrm{mol})\end{array}$ & $18.2 \pm 0.3$ & $20.1 \pm 0.2$ & $19.4 \pm 0.2$ & $18.2 \pm 02$ & $16.9 \pm 0.4$ & $17.4 \pm 0.2$ \\
\hline
\end{tabular}



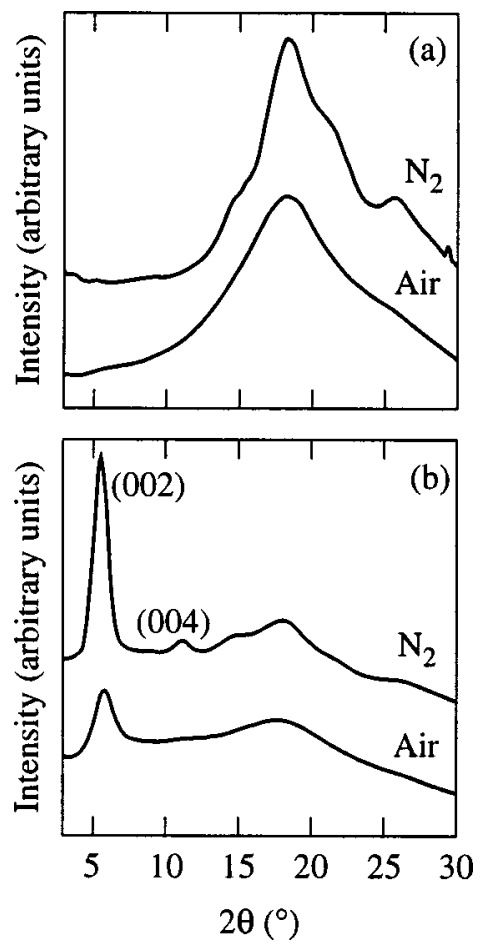

FIG. 6. X-ray diffraction patterns of vapor-deposited polyimide imidized in nitrogen and air: (a) reflection mode; (b) transmission mode.

mosphere. The air-imidized samples possessed higher permeability and lower activation energy for permeation within the measured temperature range. Figure 6 displays the x-ray diffraction patterns of the nitrogen- and air-imidized samples. The reflection-mode patterns are essentially featureless, resembling amorphous materials, while the transmission patterns contain distinct diffraction peaks. The strong 002 diffraction peak at $\sim 5.7^{\circ} 2 \theta$ is characteristic of PMDA-ODA polyimide, ${ }^{16,17}$ whose presence in the transmission mode and absence in the reflection mode indicates that the 001 lattice planes were aligned preferentially perpendicular to the film surface; namely, the chain axes were preferentially parallel to the surface. The unit cell structure is illustrated in Fig. $7 .^{18}$ Compared with the $\mathrm{N}_{2}$-imidized samples, the air-imidized samples showed a significantly weaker 002 peak, indicating a lower degree of crystallinity and/or poorer crystal alignment. Table II lists the density of the vapor-deposited polyimide imidized under different conditions. The lower density of the air-imidized samples confirmed their lower degree of crystallinity, as the degree of crystallinity $\left(x_{c}\right)$ is given by ${ }^{19}$

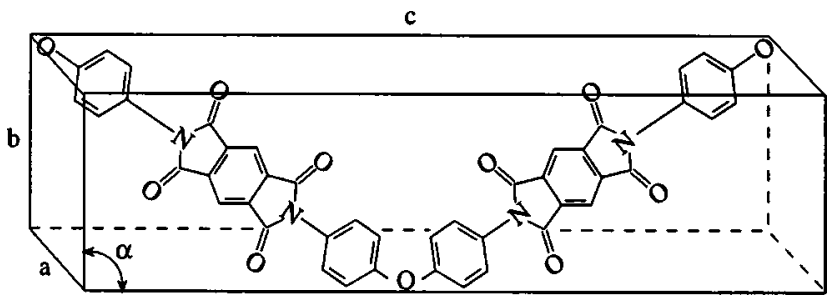

FIG. 7. Unit cell structure of PMDA-ODA polyimide crystallites. The unit cell is orthorhombic with lattice constants: $a=6.31, b=3.97, c=32 \AA$, and $\alpha=\beta=\gamma=90^{\circ}$. (see Ref. 18).
TABLE II. Density of vapor-deposited polyimide imidized under different conditions.

\begin{tabular}{lccccc}
\hline \hline & \multirow{4}{*}{$\begin{array}{c}\text { Air } \\
\text { imidized }\end{array}$} & $0.1{ }^{\circ} \mathrm{C} / \mathrm{min}$ & $1{ }^{\circ} \mathrm{C} / \mathrm{min}$ & $5^{\circ} \mathrm{C} / \mathrm{min}$ & $10^{\circ} \mathrm{C} / \mathrm{min}$ \\
\hline $\begin{array}{lccccc}\text { Density } \\
\left(\mathrm{gm} / \mathrm{cm}^{3}\right)\end{array}$ & 1.420 & 1.428 & 1.428 & 1.428 & 1.428 \\
\hline \hline
\end{tabular}

$$
x_{c}=\frac{\rho_{\mathrm{bulk}}-\rho_{a}}{\rho_{c}-\rho_{a}},
$$

where $\rho_{\text {bulk }}$ is the bulk density and $\rho_{a}$ and $\rho_{c}$ the density of polyimide in purely amorphous and crystalline morphology, respectively. The high permeability and low activation energy for permeation of air-imidized samples may be attributed to their low degree of crystallinity, as permeation through semicrystalline polymers proceeds mainly through the amorphous regions, with the crystalline regions serving as permeation barriers and limiting the mobility of the amorphous polymer chains. ${ }^{20}$

Figure 8 displays the temperature-permeability relationships and the activation energy for permeation of the vapordeposited polyimide imidized at $0.1,1,5$, or $10^{\circ} \mathrm{C} / \mathrm{min}$ in nitrogen. The permeability increased with the heating rate, while the activation energy for permeation showed an opposite trend within the measured temperature range. Examination of the transmission and grazing-angle x-ray diffraction patterns in Fig. 9 yields the following observations: (1) The diffraction peaks, most noticeably 002 , increased in intensity with the heating rate, which indicated a higher degree of crystallinity and/or better alignment of the $00 \ell$ lattice planes perpendicular to the film surface. (2) The width of the 002 peak narrowed with the heating rate, which indicated a larger crystallite size. The corresponding correlation length, a measure of the crystallite size, was estimated using Eq. (4) to be 64 and $75 \AA$ for the 0.1 and $5{ }^{\circ} \mathrm{C} / \mathrm{min}$ heating rates, respectively. (3) In the grazing-angle pattern, the $0.5^{\circ} \mathrm{C} / \mathrm{min}$ samples showed shorter 002 diffraction arcs when compared with the $0.1^{\circ} \mathrm{C} / \mathrm{min}$ samples, which indicated better align-

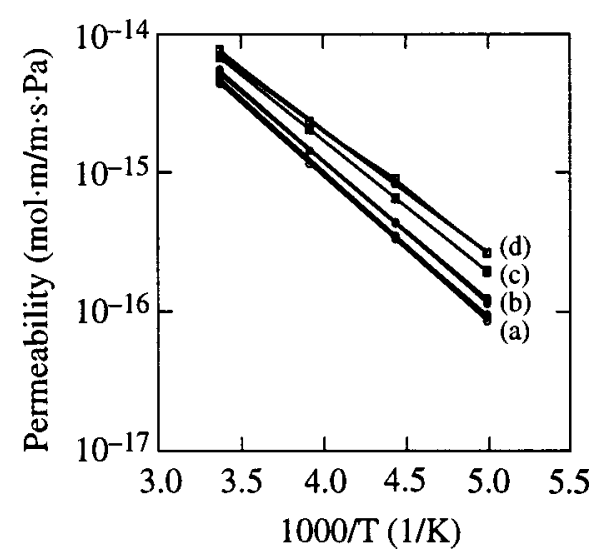

FIG. 8. Temperature dependency of the helium permeability through vapordeposited polyimide imidized at (a) 0.1 , (b) 1 , (c) 5 , and (d) $10^{\circ} \mathrm{C} / \mathrm{min}$. The activation energy of permeation was 20.1, 19.4, 18.2, and $16.9 \mathrm{~kJ} / \mathrm{mol}$ for (a), (b), (c), and (d), respectively. 

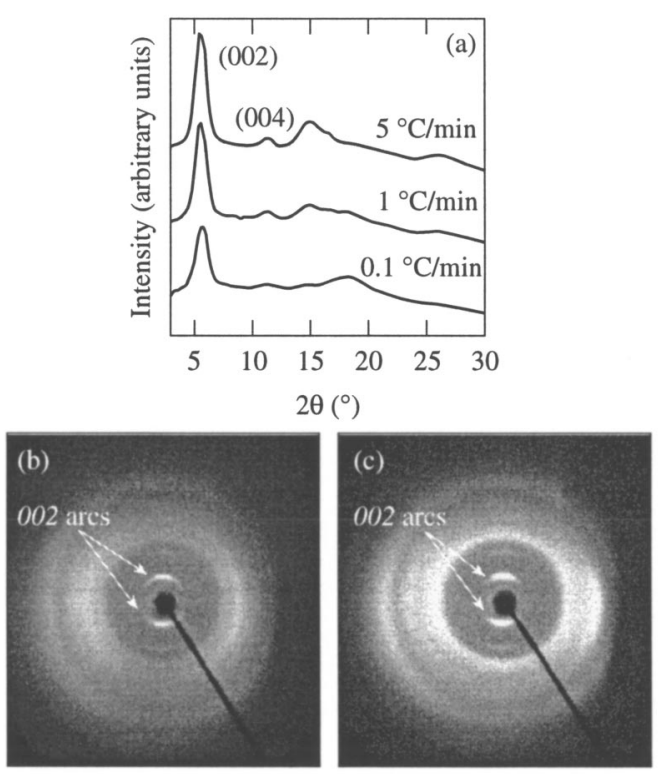

FIG. 9. X-ray diffraction patterns of vapor-deposited polyimide imidized in nitrogen at various heating rates: (a) transmission mode; (b) grazing angle mode for $0.1{ }^{\circ} \mathrm{C} / \mathrm{min}$; (c) grazing angle mode for $1{ }^{\circ} \mathrm{C} / \mathrm{min}$. Note that the dark stripe extending from the bottom to the center of (b) and (c) is the shadow of the x-ray beam stop.

ment of the $00 \ell$ lattice planes as consistent with observation (1). The identical density of samples imidized at different heating rates, as shown in Table II, suggests that the degree of crystallinity was the same regardless of the heating rate. Given the same degree of crystallinity, the samples with larger crystallite size must also contain fewer crystallites. Based on the above observations, it may be summarized that as the heating rate of imidization increased, fewer crystallization nuclei were generated, but the fewer nuclei grew into larger crystallites that were better aligned.

The higher permeability and lower activation energy for permeation of polyimide imidized at higher heating rates may be attributed to a combined effect of the following mechanisms: (1) The samples imidized at higher heating rates contained larger and fewer crystallites, which implied sparser distribution of the crystallites in the samples. Consequently, the amorphous polymer chains between crystalline regions were longer, allowing greater chain segmental mobility to expedite permeation and to lower the activation energy for permeation. (2) The higher heating rates resulted in better alignment of the $00 \ell$ lattice planes perpendicular to the film surface, which corresponded to better alignment of the chain axes parallel to the surface. This may have increased the permeability measured across the sample thickness, as permeability in the direction perpendicular to the chain axes is generally higher than that along the axes. ${ }^{20}$

\section{CONCLUSION}

The Young's modulus of vapor-deposited polyimide increased as the temperature lowered from 573 to $10 \mathrm{~K}$, with the gas permeability decreased following the Arrhenius' relationship. Imidizing in air instead of nitrogen lowered the degree of crystallinity to increase the permeability and reduce the activation energy for permeation. Imidizing in nitrogen at faster heating rates rendered no observable effect on the degree of crystallinity but resulted in larger and fewer crystallites with better-aligned lattice planes, which combined to provide greater chain segmental mobility and permeation anisotropy, thereby increasing the measured permeability and reducing the activation energy for permeation.

\section{ACKOWLEDGMENTS}

The authors thank Roger Gram for designing and constructing the cryogenic buckle testing apparatus, Sal Scaratino for assistance in building the cryogenic permeation testing apparatus. Stephen Noyes and David Turner for assistance in assembly of samples for permeation tests, James Wang for conducting preparatory cryogenic permeability measurements, and Emmanuel Alfonso for designing and constructing the deposition system. This work was supported by the U. S. Department of Energy Office of Inertial Confinement Fusion under Cooperative Agreement No. DEFC03-92SF19460, the University of Rochester, and the New York State Energy Research and Development Authority. The support of DOE does not constitute an endorsement by DOE of the views expressed in this article.

${ }^{1}$ E. L. Alfonso, S. H. Chen, R. Q. Gram, and D. R. Harding, J. Mater. Res. 13, 2988 (1998).

${ }^{2}$ C. C. Roberts, S. A. Letts, M. D. Saculla, E. J. Hsieh, and R. C. Cook, Fusion Technol. 35, 138 (1999).

${ }^{3}$ F.-Y. Tsai, E. L. Alfonso, D. R. Harding, and S. H. Chen, J. Phys. D 34, 3011 (2001)

${ }^{4}$ M. Hausladen, K. A. Lasala, and C. R. F. Lund, Chem. Eng. Commun. 143, 91 (1996).

${ }^{5}$ T. Tanaka, K. Hosoyama, K. Hara, T. Saito, S. Takabayashi, Y. Okamoto, Y. Toda, K. Nojima, M. Mori, and H. Sunaga, in Advances in Cryogenic Engineering, edited by L. T. Summers (Plenum, New York, 1996), Vol. 42, Part A, p. 21.

${ }^{6}$ J. R. Salem, F. O. Sequeda, J. Duran, W. Y. Lee, and R. M. Yang, J. Vac. Sci. Technol. A 4, 369 (1986).

${ }^{7}$ M. Iijima, Y. Takahashi, K. Inagawa, and A. Itoh, J. Vac. Soc. Jpn. 28, 437 (1985).

${ }^{8}$ B. W. McQuillan, A. Nikroo, D. A. Steinman, F. H. Elsner, D. G. Czechowicz, M. L. Hoppe, M. Sixtus, and W. J. Miller, Fusion Technol. 31, 381 (1997).

${ }^{9}$ W. C. Young, in Roark's Formulas for Stress \& Strain, 6th ed. (McGrawHill, New York, 1989), Chap. 13, p. 647.

${ }^{10}$ Kapton ${ }^{\circledR}$ product literature, DuPont ${ }^{\mathrm{TM}}$ High Performance Polymers, Circleville, OH 43113.

${ }^{11}$ R. Jenkins and R. L. Snyder, Introduction to X-Ray Powder Diffractometry (Wiley, New York, 1996), Chap. 7, p. 173.

${ }^{12}$ B. A. Squires and K. L. Smith, in Advances in X-Ray Analysis, edited by P. K. Predecki, J. V. Gilfrich, T. C. Huang, I. C. Noyan, D. K. Bowen, C. C. Goldsmith, R. Jenkins, and D. K. Smith (Plenum, New York, 1995), Vol. 38, p. 511.

${ }^{13}$ M. Kakudo and N. Kasai, X-Ray Diffraction by Polymers (Elsevier, Tokyo, 1972), p. 329.

${ }^{14}$ A. Singh-Ghosal and W. J. Koros, Ind. Eng. Chem. Res. 38, 3647 (1999).

${ }^{15}$ M. Hedenqvist and U. W. Gedde, Prog. Polym Sci. 21, 299 (1996).

${ }^{16}$ J. R. Ojeda and D. C. Martin, Macromolecules 26, 6557 (1993).

${ }^{17}$ J. Y. Liu, S. Z. D. Cheng, F. W. Harris, B. S. Hsiao, and K. H. Gardner, Macromolecules 27, 989 (1994).

${ }^{18}$ L. G. Kazaryan, D. Ya. Tsvankin, B.M. Ginzburg, Sh. Tuichiev, L. N. Korzhavin, and S. Ya. Frenkel, Vysokomol. Soedin., Ser. A 14, 1199 (1974).

${ }^{19}$ F. W. Billmeyer, Jr., Textbook of Polymer Science, 3rd ed. (Wiley, New York, 1984), Chap. 12, p. 281.

${ }^{20}$ A. Peterlin, J. Macromol. Sci., Phys. B11, 57 (1975). 